\title{
Predictors of quality of life and symptom severity in attention deficit/hyperactivity disorder
}

\begin{abstract}
Introduction: ADHD is a major reason for the referral of children and adolescents to health care services due to the multidimensional nature of the impairment experienced by patients with this disorder. As such, the aim of this study was to determine whether neuropsychological and academic performance act as significant predictors of symptom intensity and quality of life in children and adolescents with ADHD.
\end{abstract}

Method: The sample consisted of 96 children/adolescents with a diagnosis of ADHD, aged between 6 and 16 years (mean=10.23; SD=2.37). Symptom intensity was assessed using the SNAP-IV. The APT was used to evaluate school performance. Neuropsychological assessments were obtained using the WISC-III. Quality of life was determined using the Peds-QL4.0. Results were examined using correlation analysis and general linear models (GLMs).

Results: Univariate analyses revealed a significant influence of gender on the severity of inattention and hyperactivity symptoms, as well as physical QOL. Age only influenced the severity of inattention symptoms and the social domain of QOL. The school domain of QOL was predicted by writing, arithmetic, reading and total scores on the APT. Multivariate analyses revealed a significant impact of neuropsychological performance on symptom severity and social quality of life. Academic performance predicted scores on the physical, emotional and social domains of QOL.

Discussion: The variables examined in the present study were significant predictors of inattention and hyperactivity symptoms in children and adolescents with ADHD.
Volume I Issue 6 - 2017

\section{Paula Lemes, Marina Celestino Soares, Wallisen Tadashi Hattori, Nívea de Macedo Oliveira Morales}

Graduate School of Health Sciences, Universidade Federal de Uberlândia (UFU), Brazil

\author{
Correspondence: Paula lemes, Graduate Program of Health \\ Sciences. Universidade Federal de Uberlândia, Brazil,Tel \\ +55(34)3225-8628/+55(34)99166-5918, \\ Email paulinha_lemes@hotmail.com
}

Received: August 2I, 2017 | Published: September 21, 2017

Keywords: ADHD, neuropsychology, child development, quality of life, adolescence

Abbreviations: PEDS-QL, pediatric quality of life inventory; SNAP-IV, ADHD symptom severity questionnaire; APT, academic performance test; WISC-III, wechsler intelligence scale for children; ADHD, attention deficit/hyperactivity disorder

\section{Introduction}

ADHD is one of the most widely studied conditions in schoolage children, and a major reason for referral to health care services due to the multidimensional nature of the impairment experienced by patients with this disorder. ${ }^{1}$ The prevalence of ADHD in the pediatric population is estimated to be $7 \% .^{2}$ ADHD is characterized by symptoms of inattention, hyperactivity and impulsivity, with onset before age 12, which often continue into adolescence and adulthood, in one of three forms of clinical presentation: combined, predominantly inattentive, and predominantly hyperactive/impulsive (APA, 2013). According to expert opinion ${ }^{3}$ and patients themselves ${ }^{4}$ the most common functional impairments in ADHD are associated with neuropsychological performance (especially attention) ${ }^{3}$ school performance and social functioning. ${ }^{3,4}$

The presence of neuropsychological impairments in patients with ADHD relative to control subjects is corroborated by studies involving neuropsychological assessment, especially of the executive functions..$^{5-7}$ However, short-term memory is the only cognitive function to have shown a specific association with the severity of hyperactivity symptoms. ${ }^{8}$ There is no consensus in the literature regarding the association between the clinical presentation of ADHD and specific patterns of cognitive impairment. Executive functioning profiles, for instance, have been found to vary widely between patients. ${ }^{9}$ There is also a need for additional research into the association between symptom severity and neuropsychological performance in these populations.

Academic achievement studies have identified significant impairments in adolescents with ADHD relative to control subjects. ${ }^{10-12}$ Difficulties in reading and writing in ADHD have been attributed to alterations in working memory and described as a secondary consequence of self-regulation and attentional deficits inherent to the disorder. ${ }^{12}$ Adolescents with ADHD report several difficulties related to school, home, leisure and social activities, corroborating the reports of their caregivers. ${ }^{4}$ However, these issues have only been investigated through correlational or association studies, precluding the identification of causal relationships between the variables studied.

In addition to studying functional impairment, studies of ADHD have also investigated the impact of the condition on quality of life (QOL). ${ }^{13}$ QOL is defined as the perceived well-being and satisfaction of an individual with their position in life in the context of the culture and value systems in which he lives ${ }^{14}$ or, alternatively the satisfaction of desires and wishes. ${ }^{15} \mathrm{It}$ is a subjective and multidimensional concept, which taps into physical characteristics, psychological status, personal beliefs, social relationships and the individual's environment. ${ }^{14}$ Health-related quality of life (HRQOL) refers to the influence of health on perceived well-being. ${ }^{16}$ ADHD has a negative impact on QoL ${ }^{17}$ both according to the children/adolescents themselves ${ }^{13,18,19}$ and their caregivers ${ }^{13,18-20}$ especially in the psychosocial domain. ${ }^{13,19}$ There is still a need for additional research into the predictors and causes of poor QoL in children with ADHD. ${ }^{13,19}$ 
The identification of predictive and causal relationships between factors associated with ADHD allows for a better comprehension of this condition and a deeper, multidimensional understanding of this area of research. In light of these observations, the aim of this study was to verify whether neuropsychological and academic performance act as predictors of QoL and the severity of inattention and hyperactivity symptoms in children and adolescents with ADHD. We also sought to investigate the effects of gender and age on QoL and symptom severity in this population.

\section{Method}

\section{Participants}

The sample consisted of 96 children and adolescents aged 6 to 16 years, with a diagnosis of ADHD. Patients were evaluated between August 2014 until June 2016 in a university reference hospital. Sample size was calculated using $G^{*}$ Power $3.1 .^{21}$ The following parameters were considered: statistical power $=0.95$, alpha error rate $=0,05$, effect size $\mathrm{F}^{2}=0.35$ (high) and 11 possible predictors (Verbal IQ, Performance IQ, Full Scale IQ, Verbal Comprehension Index, Perceptual Organization Index, Freedom from Distractibility Index, Processing Speed Index, Arithmetic Score, Writing Score, Reading Score, Total Achievement Score). The minimum sample size required for the GLM analysis was 83 participants.

\section{Procedures}

Participants were diagnosed by a neuropediatrician according to DSM-V criteria. Only participants with normal or corrected vision were included in the study. Children/adolescents with incapacitating neurological or psychiatric conditions, such as cerebral palsy, autism, major depressive disorder, untreated metabolic disease, speech or motor impairments, were not included in the study. The presence of these conditions was determined by the neuro pediatrician. All experimental procedures were performed in accordance with ethical standards. Legal guardians provided written informed consent to their children's participation in the study, and all participants aged 12 years or older signed an informed consent form, as recommended by CNS Resolution 196/96 for research with human subjects. This study was approved by an institutional ethics committee under project number 668.685 and CAAE number 23541914.5.0000.5152.

Participants were asked to suspend stimulant medication (methylphenidate or lisdexamfetamine) for at least 12 hours prior to neuropsychological assessment. The temporary disruption in medication use was supervised by a neuropediatrician. However, it is important to note that most participants had only been recently diagnosed and had never received stimulant treatment for ADHD. Two assessment sessions were conducted with each child on two separate days instruments were administered in the following order: half the WISC-III and the PEDS-QL in session 1, half of the WISC-III and the APT in session 2. Participant characteristics are shown in Table 1.

\section{Instruments}

Participants completed four assessment instruments. The SNAP$\mathrm{IV}^{22,23}$ is a rating scale for parents/guardians and teachers based on DSM criteria for ADHD. Items are scored on a Likert scale ranging from 0 to 3 (not at all, just a little, quite a bit, very much). Symptoms of inattention and hyperactivity are measured by nine items each. In the present study, the SNAP-IV was administered to the caregiver who spends the most time with the child/adolescent during the first neuropsychological assessment session. Mean scores were calculated for each symptom domain for later analysis. ${ }^{23}$

Table I Sample characteristics

\begin{tabular}{lllll}
\hline & $\begin{array}{l}\text { Inattentive presentation } \\
\mathbf{N = 4 5}\end{array}$ & $\begin{array}{l}\text { Hyperactive presentation } \\
\mathbf{N = 2}\end{array}$ & $\begin{array}{l}\text { Combined } \\
\text { presentation } \mathbf{n = 4 9}\end{array}$ & Total $\mathbf{N = 9 6}$ \\
\hline Male, $\mathrm{n}(\%)$ & $32(33.33)$ & $2(2.08)$ & $43(44.79)$ & $77(80.20)$ \\
Age, mean years (SD) & $10.94(2.46)$ & $9.50(2.12)$ & $9.74(2.23)$ & $10.23(2.37)$ \\
\hline
\end{tabular}

The Academic Performance Test (APT) was developed by Stein ${ }^{24}$ validated for use in 2nd through 6th graders (children aged 5 to 11). Normative data is also available for children aged 11 years or older. The APT evaluates writing, arithmetic and reading skills, providing standardized scores for each section, in addition to a total score for each child/adolescent.

The Wechsler Intelligence Scale for Children ${ }^{25,26}$ has been validated for children between the ages of 6 years to 16 years 11 months. The instrument evaluates attention, concentration, processing speed, freedom from distractibility, and reasoning skills on a scale composed of 12 subtests. WISC-III was chosen as a research instrument rather than WISC-IV (Wechsler, 2013) after evaluating the cost-benefit ratio of the evaluation instruments. In the analysis performed, WISC-III proved to be useful and valid to the objectives of this study, it is accepted by the System of Evaluation of Psychological Tests (SATEPSI) of the Federal Council of Psychology in Brazil and attendance to the proposed statistical analyzes. Another important factor analyzed was the cost of the WISC-IV and its protocols that would make it unusable for research purposes, since it is necessary to carry out all research involving several instruments, not only WISC. Therefore, WISC-III met all the necessary requirements for this study purposes.

The Pediatric Quality of Life Inventory $4.0^{27,28}$ is a measure of HRQoL for children and adolescents aged 2 to 18 . The questionnaire comes in two different versions (child/adolescent and caretaker). The PEDS-QL contains 23 items, divided into four domains (physical, emotional, social and school). Each item is scored on a Likert scale ranging from 0 to 4 (never, almost never, sometimes, often, almost always) based on the last month prior to the assessment. Higher scores are indicative of a higher HRQoL. ${ }^{29}$ In the present study, the questionnaire was only administered to the children/adolescents themselves.

\section{Statistical analysis}

Data were analyzed using descriptive statistics, as well as Pearson and Spearman correlations. General linear models (GLM) were also used to investigate the impact of each independent variable on children/adolescents with ADHD. No violations of GLM assumptions 
were identified (linearity, normality and homogeneity of variance). Data quality was determined by an analysis of floor and ceiling effects $(<15 \%)$ for each variable Bennett et al. Ceiling effects were observed on SNAP-IV scores, due to the clinical characteristics of the sample (presence of ADHD). Floor effects were observed on PEDS-QL scores. There is no consensus in the literature regarding impairments in QOL in children with ADHD, with some studies suggesting that these individuals' perceived QOL does not differ from that reported by control participants, or from caretaker assessments. Nevertheless, some studies suggest that children with ADHD may experience reduced quality of life. ${ }^{13,19}$
The reliability (Cronbach's alpha) of the instruments used in the present study was also analyzed, as shown in Table 2. Values equal to or greater than 0.7 were considered satisfactory. ${ }^{29}$ The main effect of each independent variable on symptom severity and QOL were evaluated separately. The effects of any interactions between independent variables on symptom severity and quality of life were also verified. Participants with a Full-Scale IQ below $80(n=7){ }^{30}$ or who no longer wished to take part in the study $(n=15)$ were excluded from the analysis. The final sample of 96 participants had no missing data and met all inclusion criteria and no exclusion criteria for the study.

Table 2 Descriptive analysis of assessment data

\begin{tabular}{|c|c|c|c|c|c|c|c|}
\hline Instrument & $\begin{array}{l}\text { Reliability } \\
\text { (Cronbach'S A) }\end{array}$ & Variables & $\mathbf{N}$ & $\begin{array}{l}\text { Floor } \\
\text { Effect }\end{array}$ & $\begin{array}{l}\text { Ceiling } \\
\text { Effect }\end{array}$ & Mean & $\begin{array}{l}\text { Standard } \\
\text { Deviation }\end{array}$ \\
\hline \multirow[t]{2}{*}{ SNAP } & 0.864 & Inattention & 96 & $3.90 \%$ & $34.70 \%$ & 2.09 & 0.47 \\
\hline & & Hyperactivity & 96 & $14.80 \%$ & $32.07 \%$ & 1.78 & 0.78 \\
\hline \multirow[t]{7}{*}{ WISC-III } & 0.926 & Verbal IQ & 96 & $0 \%$ & $0 \%$ & 95.25 & 18.29 \\
\hline & & Performance IQ & 96 & $0 \%$ & $0 \%$ & 96.34 & 14.66 \\
\hline & & Full Scale IQ & 96 & $0 \%$ & $0 \%$ & 95.28 & 15.87 \\
\hline & & Verbal Comprehension & 96 & $0 \%$ & $0 \%$ & 97.39 & 19.29 \\
\hline & & Perceptual Organization & 96 & $0 \%$ & $0 \%$ & 97.70 & 15.00 \\
\hline & & $\begin{array}{l}\text { Freedom from } \\
\text { Distractibility }\end{array}$ & 96 & $0 \%$ & $0 \%$ & 85.00 & 14.37 \\
\hline & & Processing speed & 96 & $0 \%$ & $0 \%$ & 91.19 & 13.34 \\
\hline \multirow[t]{4}{*}{ SAT } & 0.837 & Writing & 96 & $2.50 \%$ & $0 \%$ & 16.88 & 10.60 \\
\hline & & Arithmetic & 96 & $2.50 \%$ & $0 \%$ & 11.03 & 6.75 \\
\hline & & Reading & 96 & $5 \%$ & $0 \%$ & 50.67 & 22.98 \\
\hline & & Total Score & 96 & 0 & $0 \%$ & 78.56 & 37.51 \\
\hline \multirow[t]{4}{*}{ Peds-QL } & 0.788 & Physical & 96 & $51.27 \%$ & $5.08 \%$ & 79.32 & 14.77 \\
\hline & & Emotional & 96 & $26.27 \%$ & $15.00 \%$ & 67.56 & 17.96 \\
\hline & & Social & 96 & $48.13 \%$ & $7.11 \%$ & 74.93 & $|8.6|$ \\
\hline & & School & 96 & $21.18 \%$ & $14.74 \%$ & 61.67 & 17.87 \\
\hline
\end{tabular}

Note: SNAP,ADHD symptom severity scale;WISC, wechsler intelligence scale for children; IQ, intellectual quotient; SAT, school achievement test; PEDS-QL, quality of life scale.

\section{Results}

The descriptive analysis of assessment data is shown in Table 2.

\section{Symptom severity}

A significant negative correlation was observed between Arithmetic scores on the APT and the severity of hyperactivity symptoms ( $\mathrm{r}=-$ $0.275 ; p=0.007$ ). No significant correlations were observed between neuropsychological performance and the severity of inattention/ hyperactivity symptoms $(\mathrm{p}>0.183)$. Age was negatively correlated with the severity of hyperactivity symptoms $(\mathrm{r}=-0.226 ; \mathrm{p}=0.027)$.

Table 3 shows the effects of gender and age on symptom severity as determined by univariate analysis (GLM). Neuropsychological had no significant effects with the severity of inattention/hyperactivity symptoms ( $>0.079$ ), even as academic performance had no other significant effects on symptom intensity $(0.240)$. The multivariate analysis of interaction effects revealed a significant impact of neuropsychological performance on the severity of inattention $\left(\mathrm{R}^{2}=0.336 ; \mathrm{p}=0.025\right)$ and hyperactivity symptoms $\left(\mathrm{R}^{2}=0.318 ; \mathrm{p}=0.043\right)$ after controlling for the effects of sex and age. The multivariate analysis of school performance and symptom severity revealed no significant effects of the former on hyperactivity symptoms ( $>0.120)$.

\section{Quality of life}

No significant correlations were observed between neuropsychological performance and QoL scores ( $p>0.108)$. 
Correlations between school performance and QoL were also nonsignificant $(\mathrm{p}>0.079)$. Age was not significantly associated with
QoL ( $>0.135)$. The effects of gender and age on QoL as determined by univariate analysis (GLM) are shown in Table 4.

Table 3 Univariate analysis of the effects of sex and age on symptom severity

\begin{tabular}{|c|c|c|c|c|c|c|c|}
\hline \multirow{3}{*}{ GLM } & & \multicolumn{6}{|c|}{ Neuropsychological performance } \\
\hline & & \multicolumn{4}{|c|}{ Gender } & \multicolumn{2}{|l|}{ Age } \\
\hline & & SS & $\mathbf{F}$ & p-value & $\mathbf{R}^{2}$ & SS & $\mathbf{F}$ \\
\hline Variables & Inattention & 1.232 & 6.242 & $0.014 *$ & 0.075 & 3.512 & 1.78 \\
\hline \multirow[t]{2}{*}{ SNAP-IV } & Hyperactivity & 2.918 & 5.094 & $0.026^{*}$ & 0.062 & 6.824 & 1.191 \\
\hline & & \multicolumn{6}{|c|}{ Academic performance } \\
\hline \multirow[t]{2}{*}{ GLM } & & \multicolumn{4}{|c|}{ Gender } & \multicolumn{2}{|l|}{ Age } \\
\hline & & SS & $\mathbf{F}$ & p-value & $\mathbf{R}^{2}$ & SS & $\mathbf{F}$ \\
\hline Variables & Inattention & 1.738 & 9.348 & $0.003^{*}$ & 0.105 & 3.758 & 2.021 \\
\hline SNAP-IV & Hyperactivity & 3.742 & 6.842 & $0.010 *$ & 0.079 & 3.118 & 0.57 \\
\hline
\end{tabular}

Note: GLM, general linear model; SS, sum of squares.

Table 4 Univariate analysis of the effects of sex and age on quality of life

\begin{tabular}{|c|c|c|c|c|c|c|c|c|c|}
\hline \multirow{3}{*}{ GLM } & & \multicolumn{8}{|c|}{ Neuropsychological performance } \\
\hline & & \multicolumn{4}{|l|}{ Gender } & \multicolumn{4}{|l|}{ Age } \\
\hline & & SS & $\mathbf{F}$ & p-value & $\mathbf{R}^{2}$ & SS & $\mathbf{F}$ & p-value & $\mathbf{R}^{2}$ \\
\hline Variables & Physical & 971.648 & 4.75 & $0.032 *$ & 0.058 & 2901.485 & 1.418 & 0.188 & 0.156 \\
\hline \multirow[t]{4}{*}{ PEDS-QL } & Emotional & 456.936 & $\mathrm{I} .344$ & 0.25 & 0.017 & 2796.744 & 0.823 & 0.608 & 0.097 \\
\hline & Social & 654.736 & 2.16 & 0.146 & 0.027 & 6083.487 & 2.007 & $0.043^{*}$ & 0.207 \\
\hline & School & 13.126 & 0.039 & 0.844 & 0.001 & 2077.971 & 0.616 & 0.796 & 0.074 \\
\hline & & \multicolumn{8}{|c|}{ Academic performance } \\
\hline \multirow[t]{2}{*}{ GLM } & & \multicolumn{4}{|l|}{ Gender } & \multicolumn{4}{|l|}{ Age } \\
\hline & & SS & $\mathbf{F}$ & p-value & $\mathbf{R}^{2}$ & SS & $\mathbf{F}$ & p-value & $\mathbf{R}^{2}$ \\
\hline Variables & Physical & 1226.595 & 6.281 & $0.014^{*}$ & 0.073 & 2706.982 & 1.386 & 0.202 & 0.148 \\
\hline \multirow[t]{3}{*}{ Peds-QL } & Emotional & 564.976 & 1.867 & 0.176 & 0.023 & 4275.372 & 1.413 & 0.19 & 0.15 \\
\hline & Social & 821.747 & 2.864 & 0.094 & 0.035 & 7059.334 & 2.46 & $0.012 *$ & 0.235 \\
\hline & School & 92.497 & 0.296 & 0.588 & 0.004 & 2023.605 & 0.647 & 0.769 & 0.075 \\
\hline
\end{tabular}

Note: GLM, general linear model; SS, sum of squares.

No other significant effects of neuropsychological performance on QoL were identified $(\mathrm{p}>0.099)$. The univariate analysis of academic performance demonstrated that writing $\left(\mathrm{R}^{2}=0.091\right.$; $\mathrm{p}=0.006)$, arithmetic $\left(\mathrm{R}^{2}=0.095 ; \mathrm{p}=0.005\right)$, reading $\left(\mathrm{R}^{2}=0.093\right.$; $\mathrm{p}=0.005)$ and total scores $\left(\mathrm{R}^{2}=0.176 ; \mathrm{p}=0.005\right)$ had a significant impact on the school domain of QOL. No other significant effects were identified in this analysis $(\mathrm{p}>0.094)$. The multivariate analysis of the interaction between neuropsychological performance and QOL revealed a significant effect of neuropsychological performance on the social domain of QOL after controlling for the effects of sex and age $\left(\mathrm{R}^{2}=0.399 ; \mathrm{p}=0.002\right)$. The results of multivariate analyses of the effects of academic performance on QoL are shown in Table 5.

Table 5 Multivariate analysis of the effects of academic performance on quality of life

\begin{tabular}{|c|c|c|c|c|c|c|c|c|}
\hline \multicolumn{9}{|l|}{ Quality Of Life } \\
\hline \multirow[t]{2}{*}{ GLM } & \multicolumn{4}{|l|}{ Physical } & \multicolumn{4}{|l|}{ Emotional } \\
\hline & SS & $\mathbf{F}$ & p-value & $\mathbf{R}^{2}$ & SS & $\mathbf{F}$ & p-value & $\mathbf{R}^{2}$ \\
\hline Corrected model & $6763.943 a$ & 2.071 & $0.014^{*}$ & 0.326 & $9701.342 b$ & 1.982 & $0.020 *$ & 0.317 \\
\hline Intercept & 282371.22 & 1556.508 & $0.000 *$ & 0.953 & 234254.8 & 861.271 & $0.000 *$ & 0.918 \\
\hline Age* Sex*Writing* Arithmetic* Reading* Total Score & 6763.943 & 2.071 & $0.014 *$ & 0.326 & 9701.342 & 1.982 & $0.020 *$ & 0.317 \\
\hline
\end{tabular}


Table Continued....

\begin{tabular}{|c|c|c|c|c|c|c|c|c|}
\hline \multicolumn{9}{|l|}{ Quality Of Life } \\
\hline \multirow[t]{2}{*}{ GLM } & \multicolumn{4}{|l|}{ Physical } & \multicolumn{4}{|l|}{ Emotional } \\
\hline & SS & $\mathbf{F}$ & p-value & $\mathbf{R}^{2}$ & SS & $\mathbf{F}$ & p-value & $\mathbf{R}^{2}$ \\
\hline Corrected model & | $4049.872 c$ & 3.186 & $0.000 *$ & 0.427 & $5282.63 \mathrm{Id}$ & 0.902 & 0.578 & 0.174 \\
\hline Intercept & $27 \mid 237.07$ & 1107.033 & $0.000 *$ & 0.935 & 175483.7 & 539.104 & $0.000 *$ & 0.875 \\
\hline Age* Sex*Writing* Arithmetic* Reading* Total Score & | 4049.872 & 3.186 & $0.000 *$ & 0.427 & 5282.631 & 0.902 & 0.578 & 0.174 \\
\hline
\end{tabular}

Note: GLM, general linear model; SS, sum of squares

\section{Discussion}

The aim of this study was to determine whether neuropsychological and school performance can predict QoL and ADHD symptom severity in children and adolescents. Sex and age exerted a significant influence on QoL as well as the intensity of both inattention and hyperactivity symptoms. Neuropsychological performance was a significant predictor of symptom severity, while academic performance predicted both symptom severity and QoL.

According to several studies in the literature, the neuropsychological assessment scores obtained by patients with ADHD are lower, though still in the normal range, than those obtained by control subjects. ${ }^{5-7}$ Neuropsychological tests evaluate attention, memory, perception, intelligence, processing speed, resistance to distraction, as well as verbal skills. ${ }^{25,31}$ The present findings showed that the neuropsychological performance of children and adolescents has a direct predictive influence on the severity of inattention and hyperactivity symptoms as assessed by participant caretakers. Sjöwall $\mathrm{D}$ et al. ${ }^{32}$ have demonstrated that neuropsychological impairments in pre-school children have a predictive influence on ADHD symptoms and academic performance throughout childhood into adolescence.

Improvements in neuropsychological performance are associated with decreased ADHD symptom severity. ${ }^{33}$ Cerebral functions may also influence the evolution of ADHD symptoms in early childhood, leading to a decrease in severity and associated impairments as a result of neural development. ADHD is a heterogeneous disorder, associated with variable patterns of impairment in the executive functions and other cognitive processes in children and adolescents. ${ }^{34}$ Neuropsychological assessment scores were also identified as significant predictors of social QOL. This domain includes the peer relationships of the child or adolescent. ${ }^{28}$ As such, the cognitive skills of children/adolescents with ADHD appear to predict the way they perceive their social relationships. The reading, arithmetic, writing and total scores on the APT accounted for 9.1, 9.5, 9.3 and 17.6\%, respectively, of the variance in school QOL. This domain of the PEDS-QL evaluates the ability to pay attention in class, the frequency with which the child forgets things, any difficulties in completing classroom activities, and the frequency with which they miss school due to illness or medical appointments. ${ }^{28}$

The association between ADHD symptoms and impaired school performance has already been discussed in several studies ${ }^{11,12}$ which have emphasized the importance of pharmacological and multidisciplinary approaches to improve academic outcomes in children with this condition. ${ }^{10}$ However, these studies were limited to a comparative analysis of academic performance in patients with ADHD and control samples, but did not identify, for instance, any predictor variables associated with this relationship. The present findings demonstrated that all measures of academic performance had a significant impact on children and adolescents with ADHD in terms of their perceived well-being and satisfaction with the school environment. The impairments associated with ADHD may have an impact on children's family, school and social environments, in addition to having a negative influence on QoL. ${ }^{13,19,27,28}$

The multivariate analysis of school performance revealed it to have a significant impact on physical, emotional and social QoL. Academic performance explained $32.6 \%$ of the variance in physical QoL, $31.7 \%$ of the variance in emotional QoL, $42.7 \%$ of the variance in social QoL.

The physical domain of QoL taps into physical health and daily activities such as walking, running, taking a bath or shower, while the emotional domain evaluates feelings and related issues reported by the child or adolescent, such as fear, sadness, nervousness, trouble sleeping or concerns about the future. The social domain of QOL evaluates their perceptions regarding peer relationships. ${ }^{28}$

The present findings suggest that academic performance may predict the levels of satisfaction reported by children and adolescents with ADHD with regards to the physical, emotional and social aspects of their QoL. The negative impact of ADHD on the QoL of children and adolescents has already been discussed in the literature. The most commonly affected areas, according to both the patients and their caretakers, are the physical and psychosocial (emotional, social and school) domains of QoL. ${ }^{19}$ Hareendran et al. ${ }^{4}$ found that adolescents with ADHD reported significant functional impairments associated with their condition, especially with regard to school, home, leisure activities and social interactions.

Univariate analyses revealed a significant influence of gender on the severity of inattention and hyperactivity symptoms, as well as physical QOL. Age only influenced the severity of inattention symptoms and the social domain of QOL. Academic performance variables were also predictive of scores on the school domain of QoL.

Multivariate analyses demonstrated a significant predictive effect of neuropsychological performance on the severity of inattention and hyperactivity symptoms, as well as the social domain of QOL. Academic performance predicted scores on the physical, emotional and social domains of QoL.

According to Swanson et al. ${ }^{22}$ the hyperactive presentation is the least common in samples with ADHD. In addition to corroborating this phenomenon, the present sample also included a higher number of boys than girls, as has been reported in previous investigations. ${ }^{1,35}$ Although sex was identified as a significant predictor in the univariate analysis, it showed only a weak association with remaining variables. Similar findings were obtained by Lee et al. ${ }^{19}$ who found that gender had a limited impact on the QoL of children and adolescents with ADHD. The authors suggest that gender may act as a moderator in 
different domains of QoL, which may explain its limited influence in the present study.

Arnett et al. ${ }^{36}$ have identified significant differences in symptom severity between boys and girls with ADHD, which appear to be moderated by cognitive variables such as processing speed, inhibition and working memory. This may explain the significance of gender as a predictor of symptom intensity in the present study. Additionally Arnett et al. ${ }^{36}$ have demonstrated that gender and symptom severity are mediated by genetic factors, suggesting the need for a more comprehensive explanatory framework for the relationship between ADHD symptom severity and gender, since there is no consensus in the literature regarding the association between these variables, many studies continue to demonstrate an absence of gender differences in the presentation of this disorder. ${ }^{9,31}$

The impact of age on the severity of inattention symptoms may be related to the developmental trajectory of the executive functions in childhood, which accompanies the maturation of cognitive attentional processes and their structural/functional neural correlates. This finding may also be attributed to an age-related increase in the use of cognitive strategies. ${ }^{37}$ The negative impact of ADHD on QoL has been demonstrated by several studies, including systematic reviews and meta-analyses. ${ }^{13,19}$ Symptom severity is negatively associated with QOL appears to decrease with age. ${ }^{13,19}$ According to metaanalysis findings, age has a negative impact on perceived satisfaction in children/adolescents with ADHD, with older patients reporting progressively lower levels of well-being. ${ }^{19}$ The present findings corroborate these observations by demonstrating the predictive influence of age on social QoL.

In this research, symptom severity was assessed by the caretakers who spend the most time with the child. Future studies may also wish to consider teacher ratings, as they spend the most time with the children/adolescents in situations requiring greater attention and impulse control. Additional measures of other variables associated with academic performance may also be of interest for future investigations. Our findings highlight the importance of moving beyond individual questions addressing the environmental and social issues reported by individuals with ADHD. Poor social competence can be associated with several impairments to life functioning, including emotional, behavioral issues, low self-esteem, anxiety and depression. According to Schei et al. ${ }^{38}$ social and individual competences are important mediators of the association between emotional issues and QoL in patients with ADHD. As such, adolescents with higher levels of social and personal competence may be less vulnerable to emotional issues and report better QoL. Another study has suggested that planning and organization skills predict academic achievement in children and adolescents aged 10 to 14 years. ${ }^{39}$

The present study also underscores the need for academic interventions for children/adolescents with ADHD, since academic development proved to be a significant predictor of physical, emotional and social well-being. Therefore, early academic interventions may improve both educational achievement and perceived satisfaction happiness in children and adolescents with ADHD. Additional studies are still required to determine the impact of variables related to $\mathrm{ADHD},{ }^{40}$ and their causal, mediating or moderating effects on each other. The present study is also relevant for health professionals who work with children and adolescents with ADHD by signaling the importance of including measures of QoL in assessment batteries, interventions, treatments and follow-up protocols. Some possible limitations of the present study include the use of subjective assessment instruments (SNAP-IV and PEDS-QL) evaluated by parent/caretaker ratings of symptom severity. Nevertheless, our findings amplify the traditional biomedical care model and provide relevant information regarding ADHD from the perspective of children and adolescents with this disorder. ${ }^{41}$

\section{Conclusion}

Neuropsychological and academic performance were significant predictors of both QoL and the severity of inattention/hyperactivity symptoms. Age and gender also emerged as significant predictors of the variables of interest.

\section{Highlights: (4 to 5 points - $\mid 20$ words maximum - end of text)}

i. Identification of predictors of quality of life and symptom severity in children with ADHD.

ii. Age and gender had a significant influence on some aspects of symptom severity and quality of life.

iii. Neuropsychological performance predicted symptom severity and scores on the social domain of quality of life.

iv. Academic performance was a predictor of physical, emotional, and social quality of life.

v. These findings and their implications must be investigated by additional studies.

\section{Acknowledgements}

This article is based on the first author's doctoral dissertation. All materials were provided by the Academic Management Office of the UFU Clinical Hospital. We extend special thanks to Tânia Maria da Silva Mendonça for her invaluable statistical assistance.

\section{Conflicts of interest}

Authors declare there is no conflict of interest in composing this manuscript.

\section{References}

1. Barkley RA, Anastopoulos AD, Robin AL, et al. Transtorno de déficit de atenção/hiperatividade: manual para diagnóstico e tratamento $3 \mathrm{rd}$ ed. Porto Alegre. Artmed, Brazil; 2008.

2. Thomas R, Sanders S, Doust J, et al. Prevalence of attention-deficit/ hyperactivity disorder: A systematic review and meta-analysis. Pediatrics. 2015;135(4):e994-1001.

3. Schipper E, Mahdi S, Coghill D, et al. Towards an ICF core set for ADHD: a worldwide expert surveyon ability and disability. Eur Child Adolesc Psychiatry. 2015;24(12):1509-1521.

4. Hareendran A, Setyawan J, Pokrzywinski R, et al. Evaluating functional outcomes in adolescents with attention-deficit/hyperactivity disorder: development and initial testing of a self-report instrument. Health Qual Life Outcomes. 2015;13(133):1-14.

5. Epstein JN, Langberg JM, Rosen PJ, et al. Evidence for higher reaction time variability for children with ADHD on a range of cognitive tasks including reward and event rate manipulations. Neuropsychology. 2011;25(4):427-441. 
6. Coghill DR, Seth S, Matthews K. A comprehensive assessment of memory, delay aversion, timing, inhibition, decision making and variability in attention deficit hyperactivity disorder: advancing beyond the three-pathway model. Psychol Med. 2014;44(9):1989-2001.

7. Kofler MJ, Alderson RM, Raiker JS, et al. Working memory and intraindividual variability as neurocognitive indicators in ADHD: Examining Competing Model Predictions. Neuropsychology. 2014;28(3):459-471.

8. Courel SF. Um estudo de associação entre sintomas de tratamento de déficit de atenção/hiperatividade e medidas neuropsicológicas em crianças em idade escolar. Trabalho de Conclusão de Especialização. Universidade federal do rio grande do sul. Rio grande do sul: Brazil; 2012 .

9. Jacobsen GM. Funções executivas na infância: impacto de idade, sexo, tipo de escola, escolaridade parental e sintomas de desatenção/ hiperatividade. Dissertação de Mestrado. PUCRS, Porto alegre, Rio grande do sul: Brazil; 2016.

10. Araújo APQC. Avaliação e manejo de crianças com dificuldade escolar e distúrbio de atenção. Jornal de Pediatria. 2002;78(Supl 1): S10-S110.

11. Bianchini MC, Fonseca LC. Transtorno de déficit de atenção/ hiperatividade: teste de desempenho escolar, inventários de comportamento e medidas do eletroencefalograma quantitativo. Anais do XIV encontro de iniciação científica da PUC-campinas; 2009.

12. Cunha VLO, Silva C, Lourencetti MD, et al. Desempenho de escolares com transtorno de déficit de atenção e hiperatividade em tarefas metalinguísticas e de leitura. Revista CEFAC. 2013;15(1):40-50.

13. Danckaerts M, Sonuga BEJS, Banaschewski T, et al. The quality of life of children with attention deficit/hyperactivity disorder: a systematic review. Eur Child Adolesc Psychiatry. 2010;19(2):83-105.

14. WHOQOL. The World Health Organization. WHOQOL: measuring quality of life; 2012.

15. Tengland PA. The goals of health work: Quality of life, health and welfare. Med Health Care Philos. 2006;9(2):155-167.

16. Hays RD, Anderson RT, Revicki D. Assessing reliability and validity of measurement in clinical trials. In: Staquet MJ, Hays RD, editors. Quality of life assessment in clinical trials.UK: Oxford University Press; 2000:169-182.

17. Velő S, Keresztény Á, Szentiványi D, et al. Quality of life of patients with attention-deficit/hyperactivity disorder: systematic review of the past 5 years. Neuropsychopharmacol Hung. 2013;15(2):73-82.

18. Dallos G, Miklósi M, Keresztény A, et al. Self- and Parent-rated quality of life of a treatment naïve sample of children with ADHD: The Impact of Age, Gender, Type of ADHD, and comorbid psychiatric conditions according to both a categorical and a dimensional approach. Journal of Attention Disorders. 2014;21(9).

19. Lee YC, Yang HJ, Chen VC, et al. Meta-analysis of quality of life in children and adolescents with ADHD: By both parent proxy-report and child self-report using PedsQL. Research in developmental disabilities. 2016. p. 51-52.

20. Laugesen B, Grønkjær M. Parenting experiences of living with a child with attention deficit hyperactivity disorder: a systematic review of qualitative evidence. JBI Database System Rev Implement Rep. 2015;13(11):169-234.

21. Faul F, Erdfelder E, Buchner A, et al. Statistical power analyses using $\mathrm{G}^{*}$ Power 3.1: Tests for correlation and regression analyses. Behavior Research Methods. 2009;41(4):1149-1160.

22. Swanson JM, Kraemer HC, Hinshaw SP, et al. Clinical relevance of the primary findings of the MTA: success rates based on severity of ADHD and ODD symptoms at the end of treatment. J Am Acad Child Adolesc Psychiatry. 2001;40(2):168-179.
23. Mattos P, Serra PMA, Rohde LA, et al. Apresentação de uma versão em português para uso no Brasil do instrumento MTA-SNAP-IV de avaliação de sintomas de transtorno do déficit deatenção/hiperatividade e sintomas de transtorno desafiador e de oposição. Revista de Psiquiatria do Rio Grande do Sul. 2006;28(3):290-297.

24. Stein LM. TDE: Teste do desempenho escolar: manual para aplicação e interpretação. São Paulo: Casa do Psicólogo: Brazil; 1994.

25. Wechsler D. WISC-III: Escala de Inteligência Wechsler para Crianças: Manual. Casa do Psicólogo. 2002;4(2):309.

26. Figueiredo VLM. WISC-III: Escala de Inteligência Wechsler para Crianças - adaptação brasileira da 3rd ed. São Paulo: Casa do Psicólogo; 2002.

27. Varni JW, Seid M, Kurtin PS. et al. Reliability and validity of the pediatric quality of life inventory ${ }^{\mathrm{TM}}$ Version 4.0 generic core scales in healthy and patient populations. Med Care. 2001;39(8):800-812.

28. Klatchoian DA, Len CA, Terreri MT RA, et al. Quality of life of children and adolescents from São Paulo: reliability and validity of the Brazilian version of the pediatric quality of life inventory TM version 4.0 Generic Core Scales. Jornal de Pediatria. 2008;84(4):308-315.

29. Cramer JA. Principles of Health-related Quality of Life: Assessment in Clinical Trials. Epilepsia. 2002;43(9):1084-1095.

30. Rajendran K, O Neill S, Marks DJ, et al. Latent profile analysis of neuropsychological measures to determine preschoolers' risk for ADHD. Journal of Child Psychology and Psychiatry. 2015;56(9):958-965.

31. Lemes P, Rossini JC. Atenção e Comportamento Inibitório em Crianças de 6 a 8 Anos. Psicologia Teoria e Pesquisa. 2014;30(4):385-391.

32. Sjöwall D, Roth L, Lindqvist S, et al. (2013) Multiple deficits in ADHD: executive dysfunction, delay aversion, reaction time variability, and emotional deficits. J Child Psychol Psychiatry. 2013;54(6):619-627.

33. Rajendran K, Rindskopf D, O Neill S, et al. Neuropsychological Functioning and Severity of ADHD in Early Childhood: A Four-Year Cross-Lagged study. J Abnorm Psychol. 2013;122(4):1179-1188.

34. Rajendran K, Trampush JW, Rindskopf D, et al. Association between variation in neuropsychological development and trajectory of ADHD severity in early childhood. Am J Psychiatry. 2013;170(10):1205-1211.

35. Rohde LA, Halpern R. Transtorno de déficit de atenção/hiperatividade: atualizado. Jornal de Pediatria. 2004;80(2):61-70.

36. Arnett AB, Pennington BF, Willcutt EG, et al. Differences in ADHD symptom severity. Journal of $J$ Child Psychol Psychiatry. 2015;56(6):632-639.

37. Arán FV. Funciones ejecutivas en niños escolarizados: efectos de la edad y del estrato socioeconómico. Avances en Psicología Latinoamericana. 2011;29(1):98-113.

38. Schei J, Novik TS, Thomsen PH, et al . Improved quality of life among adolescents with attention-deficit/hyperactivity disorder is mediated by protective factors: a cross sectional survey. BMC Psychiatry. 2015;15(108):1-10.

39. Langberg JM, Dvorsky MR, Evans SW. What Specific Facets of Executive Function are Associated with Academic Functioning in Youth with Attention-Deficit/Hyperactivity Disorder?. J Abnorm Child Psychol. 2013;41(7):1145-1159.

40. Wasserman T, Wasserman LD. The sensitivity and specificity of neuropsychological tests in the diagnosis of attention deficit hyperactivity disorder. Appl Neuropsychol Child. 2012;1(2):90-99.

41. Arlington VA. Diagnostic and statistical manual of mental disorders 5th ed.American Psychiatric Association USA; 2013. 